\title{
Oil Film and Pressure Characteristics of the Friction Pair
}

\author{
Shan Hu \\ Shanghai University of Engineering Science, Shanghai, China \\ Email: 15317652575@163.com
}

How to cite this paper: Hu, S. (2018) Oil Film and Pressure Characteristics of the Friction Pair. Open Access Library Journal, 5: e5053.

https://doi.org/10.4236/oalib.1105053

Received: November 15, 2018

Accepted: December 8, 2018

Published: December 11, 2018

Copyright (๑) 2018 by author and Open Access Library Inc.

This work is licensed under the Creative Commons Attribution International License (CC BY 4.0).

http://creativecommons.org/licenses/by/4.0/

\section{(c) (i) Open Access}

\begin{abstract}
In order to improve the friction performance of the valve plate and improve the oil film bearing capacity of the valve plate, the influence of the fluid-solid coupling on the performance of the oil film of the valve plate was studied. The lubrication characteristics of the surface texture of the valve plate were studied systematically based on the theory, simulation and coupling effects. In this paper, the geometrical model of hydraulic drive valve plate is established, and the thickness and pressure equation of hydraulic film are deduced theoretically. The Reynolds equation is solved by the finite difference methods. The film thickness and pressure distribution under fluid-solid coupling of the port plate pair are obtained, and the correctness of the theory and programming is analyzed.
\end{abstract}

\section{Subject Areas}

Mechanical Engineering

\section{Keywords}

Friction Performance, Valve Plate, Lubrication Characteristics, Friction Coefficient, Fluid-Solid Coupling

\section{Introduction}

\section{Selection of Lubrication Characteristics of Port Plate Pair Samples}

Valve plate is an important component of the axial piston pump, widely used in hydraulic power components and actuators, such as axial piston motors, hydraulic pumps and so on [1] [2]. Modern hydraulic transmission technology generally faces the goal of high-speed and high-pressure development and demands the working performance and service life of the valve plate more strictly [3] [4] [5]. An elevated fluid pressure is generated in a thin film of viscous fluid 
that is sheared between nearly parallel surfaces. This lubrication pressure supports part of the load, therefore reducing the normal stress and associated friction across the gap [6] [7]. Hydrodynamic pressure does cause the majority of pressure deformation, but the resulting nonflatness allows for greater hydrodynamic effects. The viscous fluid creates pressure by forming a wedge gap between two relatively moving surfaces; the converging wedge gap forms a hydrodynamic oil film. The fluid-solid coupling is formed considering the viscosity effect and the elastic deformation between the two metal surfaces [8] [9]. Fluid-solid coupling mechanics, as a branch of mechanics, is produced by fluid mechanics and solid mechanics [10] [11]. This paper mainly studies the influence of solid deformation on fluid and the influence of flow field on solid deformation.

Pan et al. [12] adopted a finite difference method to calculate the oil film thickness between the cylinder block and the valve plate. Cho [13] conducted the optimum design for the valve plate of an axial piston pump under high pressure by an orthogonal array to decrease the maximum stress. Bergada et al. [14] studied the leakage problem between the cylinder block and the valve plate in axial piston pump. Wang derived the formula for determining the pressure of the port plate pair based on the Reynolds equation: the pressure and temperature field distribution of oil film were numerically analyzed [15]. Ahn used the finite element method for the computation of the pressure distribution between a cylinder block and a valve plate of the axial piston pump [16]. Bergada clarified the understanding of the complex dynamics, pointing out how the oil film thickness depends on the oil pressure [17]. Rybicki and Strenkowski presented a finite element numerical solution technique for compliant bearing lubrication [18]. Mucchi and Gazzi proposed an experimental methodology for analysis of the lubrication regime and wear that occurs between vanes and the pressure ring in variable displacement vane pumps. Low wear and reduced friction can be obtained if EHL between vanes and pressure ring is established [19]. Han et al. [20] established a partial lubrication model to predict film thickness between the valve plate and cylinder block, but due to the lower speed, the centrifugal force was neglected in Reynolds equation. Lin and $\mathrm{Hu}$ [21] applied a genetic algorithm method to solve the tribodynamic model of slipper bearings, and discussed the effects of cylinder speed, loading pressure, and oil viscosity on film thickness. $\mathrm{Li}$, $\mathrm{Ji}$, and Yang analyzed the thermal-fluid structure coupling for valve plate friction pair of axial piston pump, to reveal its interior multiphysics field coupling mechanism [22].

Without regard to fluid-solid coupling, the fluid object and the solid object are independent and there is no mutual shadow. However, during the actual operation of the hydraulic motor, there is oil film force between the valve plates, which makes the valve plates elastic. The deformation of the valve plate will affect the pressure of the oil film. The effects of fluid-solid coupling on the performance of the port plate pair need to be considered comprehensively. Com- 
bined with the fluid-structure interaction theory, micro flow plate of fluid-solid coupling model is set up, the simulation implementation valve plate and the interaction between oil film, related to each other through a coupling boundary surface, analyze the complexities of fluid and solid movement at the same time, further to explore the situation of considering fluid-structure interaction, the optimal parameters effect the performance of the valve plate.

\section{Establishment of the Mathematical Model}

\subsection{Model Building}

The classical solution methods of fluid-solid coupling are analytical and semi-analytical methods, but the analytical methods are only applicable to the study area shape. The simpler case limits the scope of application. However, with the development of computing technology, finite element, boundary element, etc., numerical methods are commonly used in fluid-solid coupling analysis. The most widely used numerical method to solve partial differential equation is finite element method. There are two kinds of finite element schemes commonly used in fluid-solid coupling analysis. First is the displacement format; the other is a combination of structure displacement vector and fluid scalar as field variables, such as displacement and pressure format.

Based on the classic point contact elastic deformation theory, this paper studies the microstructure in consideration of fluid-solid coupling. The lubrication property of the textured oil film is with valve plate (Figure 1).

\subsection{Boundary Conditions}

In the process of port plate of the running motor, the pressure distribution between the valve plate pair is caused by the dynamic pressure caused by the tilt of the cylinder. Combined with static pressure due to oil passing through the waist-shaped groove, when the oil inlet of the running motor has no pressure oil or the lower pressure oil, it is assumed that the cylinder body rotates, that is,

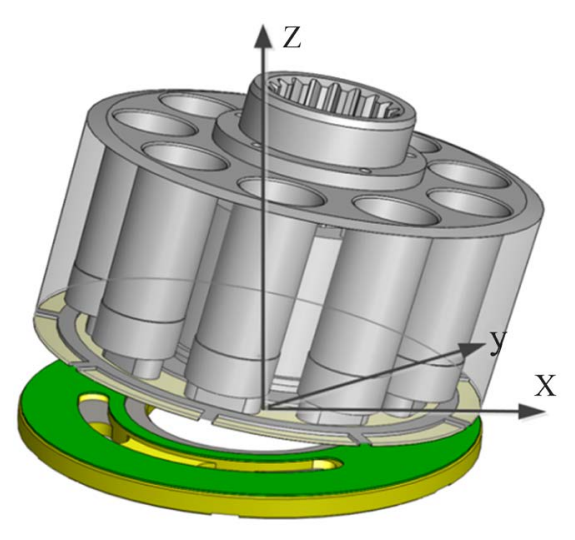

(a)

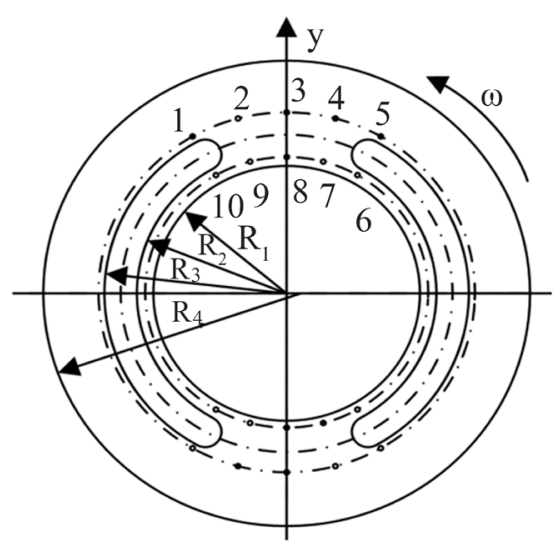

(b)

Figure 1. Mathematical model of the valve plate. 
the motor working condition becomes the pump working condition. However, when the oil inlet of the traveling motor passes through the high-pressure oil, the push force formed by the dynamic pressure and the push force formed by the micro-texture are secondary to the push force formed by the static pressure.

There are several factors that affect the pressure distribution of the distribution of port plate pair:

1) The dynamic pressure effect of the oil film on the valve plate is related to the cylinder block speed.

2) The dynamic pressure effect is affected by the hydraulic oil viscosity. The viscosity increases, the dynamic pressure effect increases, the viscosity decreases, and the dynamic pressure effect decreases.

3) The dynamic pressure effect is affected by the inclination angle of the motor cylinder, the tilt angle of the cylinder is increased, and the dynamic pressure effect generated by the running of the motor is enhanced.

For the setting of the boundary conditions of the valve plate, the low-pressure side of the valve plate is set as atmospheric pressure, and the high-pressure side of the valve plate is provided by the motor. The starting pressure on the inner side of the valve plate sealing belt is $101,325 \mathrm{~Pa}$, the starting pressure on the outer side of the valve plate sealing belt is $101,325 \mathrm{~Pa}$, and the boundary pressure on the high-pressure side and low-pressure side sealing belt is 101,325 Pa.

\section{Basic Formulas for Fluid-Solid Coupling}

\subsection{Numerical Calculation}

The fluid-solid coupling studied in this paper does not consider the influence of temperature, the basis of the problem of fluid-solid coupling equation at isothermal point. This equation includes Reynolds equation, oil film thickness equation, deformation equation, viscous pressure equation and dense pressure equation.

Reynolds equation:

$$
\frac{\partial}{\partial r}\left(\frac{r h^{3}}{\eta} \frac{\partial p}{\partial r}\right)+\frac{1}{r} \frac{\partial}{\partial \theta}\left(\frac{h^{3}}{\eta} \frac{\partial p}{\partial \theta}\right)=6 \omega r \frac{\partial h}{\partial \theta}
$$

Film thickness equation:

$$
\begin{aligned}
& h(x, y)=h_{c}+v(x, y) \\
& h_{c}=h_{O}+R \sin \theta \tan \varphi
\end{aligned}
$$

Deformation equation:

$$
\begin{gathered}
v(x, y)=\frac{2}{\pi E} \iint_{\Omega} \frac{p(s, t)}{\sqrt{(x-s)^{2}+(y-t)^{2}}} \mathrm{~d} s \mathrm{~d} t \\
\frac{1}{E}=\frac{1}{2}\left(\frac{1-V_{1}^{2}}{E_{1}}+\frac{1-V_{2}^{2}}{E_{2}}\right)
\end{gathered}
$$

Pressure-viscosity equation: 


$$
\begin{aligned}
& \eta=\eta_{0} \exp \left\{\left(\ln \eta_{0}+9.67\right)\left[-1+\left(1+\frac{p}{p_{0}}\right)^{z}\right]\right\} \\
& z=0.68
\end{aligned}
$$

Dense-pressure equation:

$$
\rho=\rho_{0}\left(1+\frac{0.6 p}{1+1.7 p}\right)
$$

Reynolds equation of fluid-solid coupling point contact problem after dimensionless is:

$$
\frac{\partial}{\partial X}\left(\varepsilon \frac{\partial P}{\partial X}\right)+\frac{\partial}{\partial Y}\left(\varepsilon \frac{\partial P}{\partial Y}\right)=\frac{\partial(\rho * H)}{\partial X}
$$

Load equation:

$$
\int_{x_{0}}^{x_{e}} \int_{y_{0}}^{y_{e}} P(X, Y) \mathrm{d} X \mathrm{~d} Y=\frac{2}{3} \pi
$$

In the calculation of fluid-solid coupling, Reynolds equation and elastic deformation equation need to be solved simultaneously. The solution of the elastic deformation equation is actually to calculate the elastic deformation of the surface under the normal pressure distribution. The discrete form of Reynolds equation can be written as follows:

$$
\begin{aligned}
& \xi_{i-0.5, j} P_{i-1, j}+\xi_{i+0.5, j} P_{i+1, j}+\xi_{i, j-0.5} P_{i, j-1}+\xi_{i, j+0.5} P_{i, j+1}-\xi_{0} P_{i, j} \\
& =\frac{\rho_{i, j} H_{i, j}+\rho_{i-1, j} H_{i-1, j}}{\Delta X}
\end{aligned}
$$

The equation of film thickness is:

$$
\begin{gathered}
H_{i, j}=H_{0}+\frac{X_{i}^{2}+Y_{j}^{2}}{2}-\frac{1}{\pi} \sum_{k=1}^{n} \sum_{i=1}^{n} D_{i, j}^{k l} P_{k l} \\
\Delta X \Delta Y \sum_{i=1}^{n} \sum_{j=1}^{n} P_{i, j}=2 \pi / 3
\end{gathered}
$$

The point contact problem is solved using an iterative method, Since the elastotropic contact in both the viscosity-pressure equation and the film thickness equation changes with pressure, the general practice is to first give an initial pressure distribution and calculate the film thickness and lubrication viscosity. Then, the Reynolds equation was introduced to solve the new pressure distribution for iterative correction, and elastic deformation and film thickness values were recalculated and iterated, until the pressure difference obtained from the previous and previous iterations was less than the set value, and the iteration ended. Then the final pressure distribution and the film thickness with elastic deformation are calculated.

\subsection{Program Block Diagram}

Figure 2 shows the block diagram of the isothermal fluid-solid coupling calculation. 


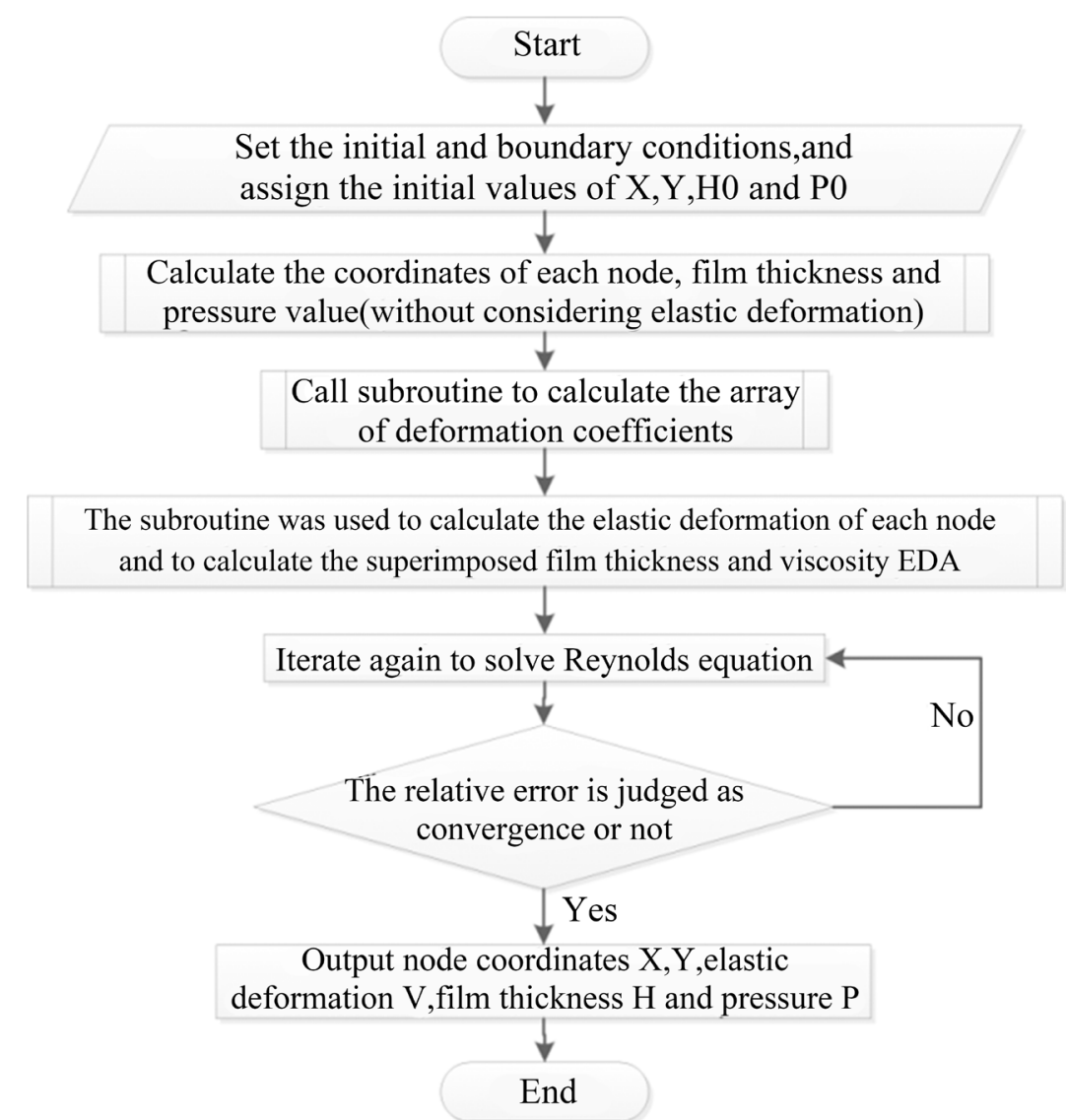

Figure 2. Block diagram of the isothermal fluid-solid coupling calculation.

\section{Oil Film Configuration and Pressure Distribution of the Valve Plate}

\subsection{Distribution Diagram of Oil Film Thickness in Valve Plate}

Figure 3 and Figure 4 show the dimensionless oil film thickness distribution of the valve plate, where Figure 3 shows the 3D diagram of the oil film distribution. It can be seen from the figure that the oil film thickness of the valve plate changes with the change of the circumferential angle of the valve plate, which is consistent with the oil film state of the valve plate in the actual situation. Figure 4 is a two-dimensional distribution diagram of the thickness of the valve plate in the inclined state of the cylinder, and its coordinate distribution corresponds to Figure 3. As can be seen from figure, when $\mathrm{x}$ positive half-axis rotates along the direction of cylinder body, namely 180 degrees clockwise, the oil film thickness of valve plate gradually becomes thinner from thickness, which is consistent with the change trend of the oil film thickness of valve plate under actual conditions, that is, the oil film in the high-pressure area of valve plate is relatively thin and the oil film in the low-pressure area is relatively thick.

\subsection{Pressure Distribution Diagram of the Oil Film in Valve Plate}

Figure 5 and Figure 6 show the dimensionless oil film pressure distribution of 


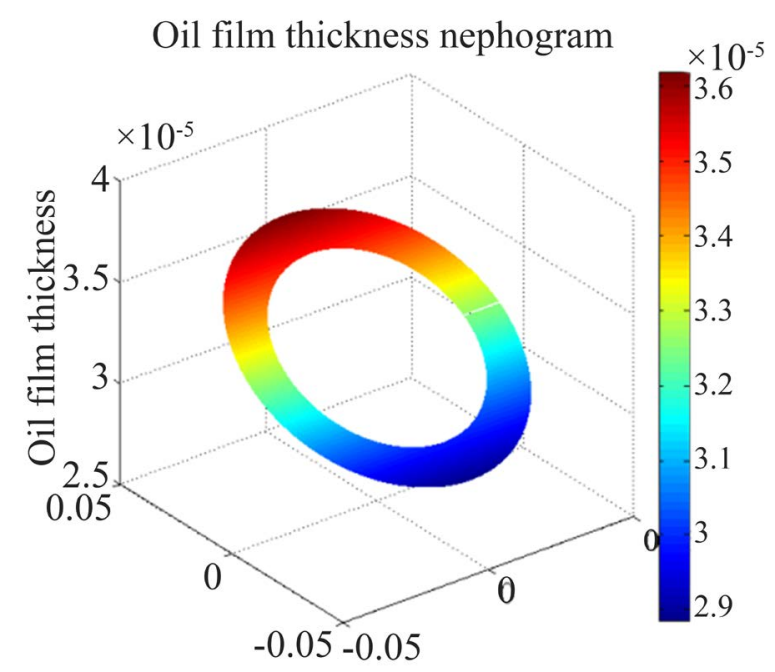

Figure 3. 3D diagram of the oil film distribution.

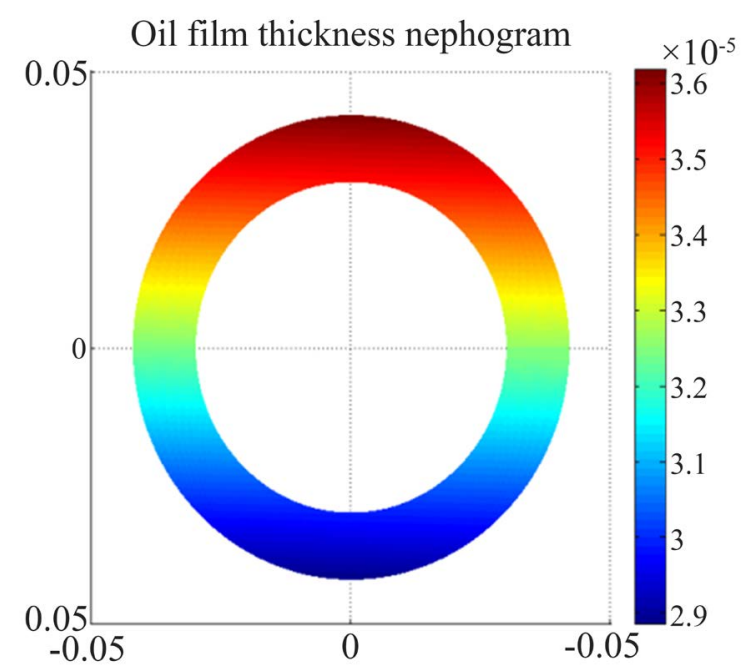

Figure 4. Top view of the wedge-shaped oil film thickness.

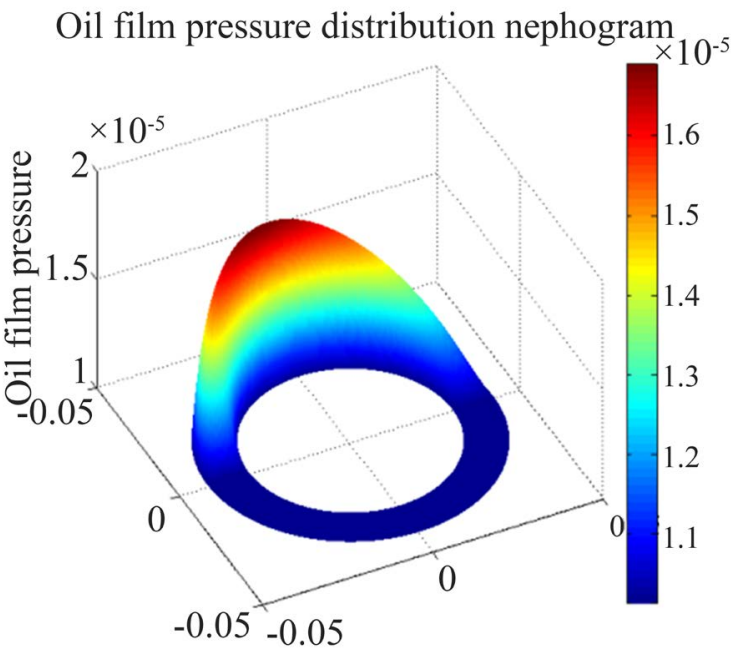

Figure 5. 3D dimensionless oil film pressure distribution. 


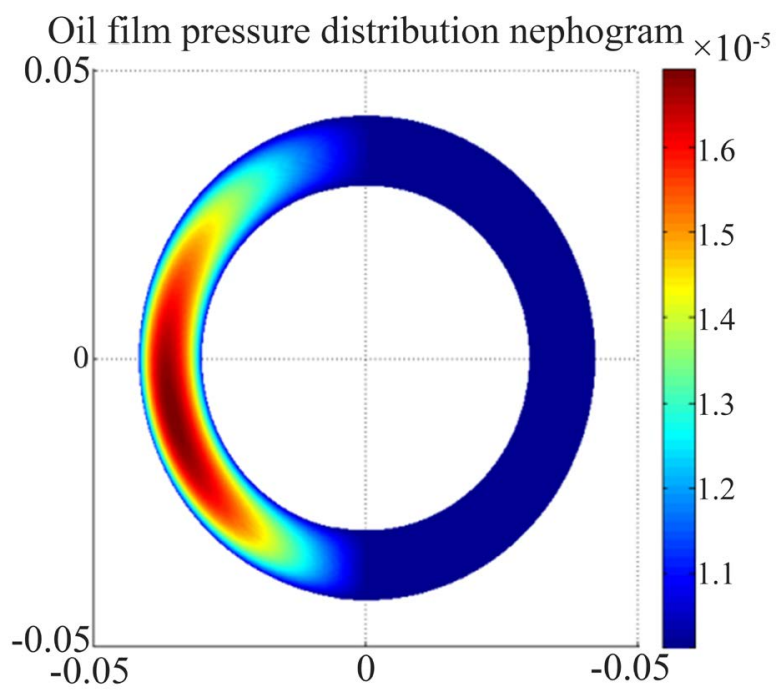

Figure 6. Top view of the dimensionless oil film pressure distribution.

the valve plate, where Figure 5 shows the three-dimensional diagram of oil film pressure distribution. local high pressure will be generated in the convergence area along the rotation direction of cylinder block, namely clockwise direction, which is consistent with the theory of forming dynamic pressure effect. Figure 6 shows the top view of the oil film pressure distribution in the tilted state of the cylinder block. The pressure of oil film increases in the third quadrant, which is the obvious area of dynamic pressure effect.

\section{The Thickness and Pressure Distribution of the Fluid Solid Coupling on the Valve Plate}

After setting the parameters and boundary conditions of the valve plate, the oil film thickness and pressure feed of the valve plate without microstructure were studied. In line programming calculation, considering fluid-solid coupling, the oil film thickness deformation distribution of the valve plate under corresponding working conditions is obtained as follows. Figure 7 shows the two-dimensional deformation of the oil film thickness of the valve plate. Figure 8 shows the two-dimensional deformation of the oil film thickness of the valve plate.

It can be seen from the figure that, considering the fluid-solid coupling, the valve plate is deformed by the oil film extrusion, and its deformation is caused. The amount is related to the pressure distribution of the oil film. It can be seen from the figure that the valve plate is elastic when considering fluid-solid coupling. The oil film thickness between the valve plate and cylinder body increases with the increase of the pressure, and the maximum deformation occurs at the maximum oil film pressure. The minimum deformation was $1.3 \%$ at the minimum pressure and $3.5 \%$ at the average deformation.

After setting the parameters and boundary conditions of the travelling motor valve plate, the oil film thickness and pressure of the micro-texture valve plate were studied. 


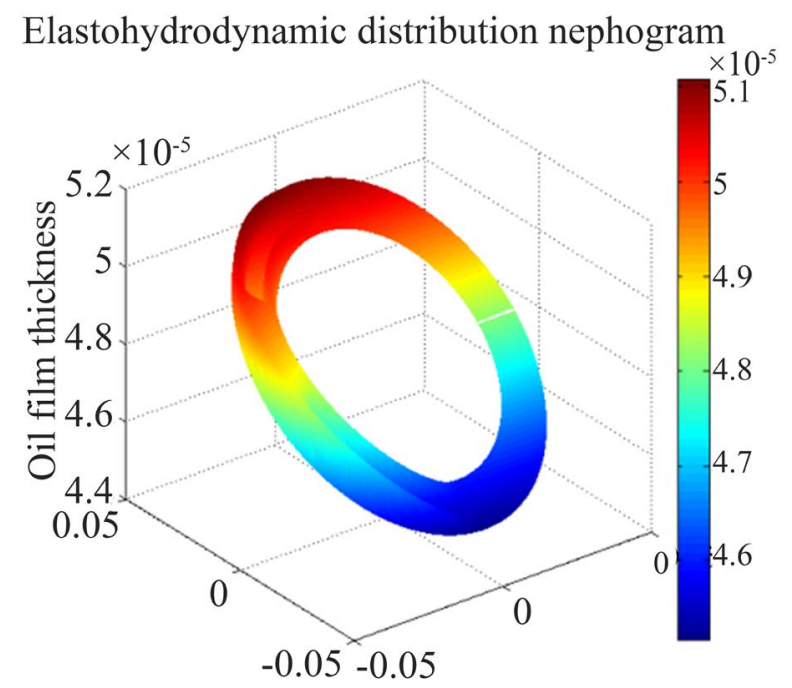

Figure 7. Fluid-structure coupling with the thickness of the oil film thickness deformation.

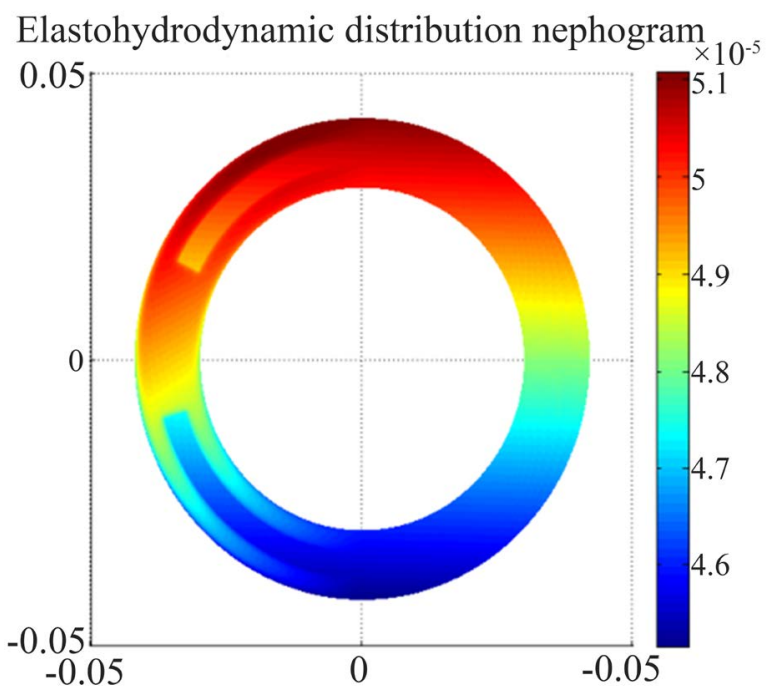

Figure 8. Oil film thickness distribution of valve plate.

According to the programming calculation, the parameters of the flow distribution disk of the hydraulic motor were taken as the values in Table 1, and programmed according to Figure 9. Under the consideration of fluid-solid coupling, the micro-texture oil film thickness and pressure distribution cloud diagram of the flow distribution disk of the corresponding working condition was obtained as shown below.

Figure 9 shows the distribution diagram of the oil film thickness of the spherical-shaped microstructure of the sphere under the optimal texture, in which the spherical-shaped microstructure is. The depth of the texture was 0.04 $\mathrm{mm}$ and the radius was $0.7 \mathrm{~mm}$. It can be seen from the figure that at the junction of the oil film and the micro-texture surface of the distribution disk, the oil film is subjected to elastic deformation, resulting in the oil film shape is no longer 
Table 1. travelling motor's valve plate parameters.

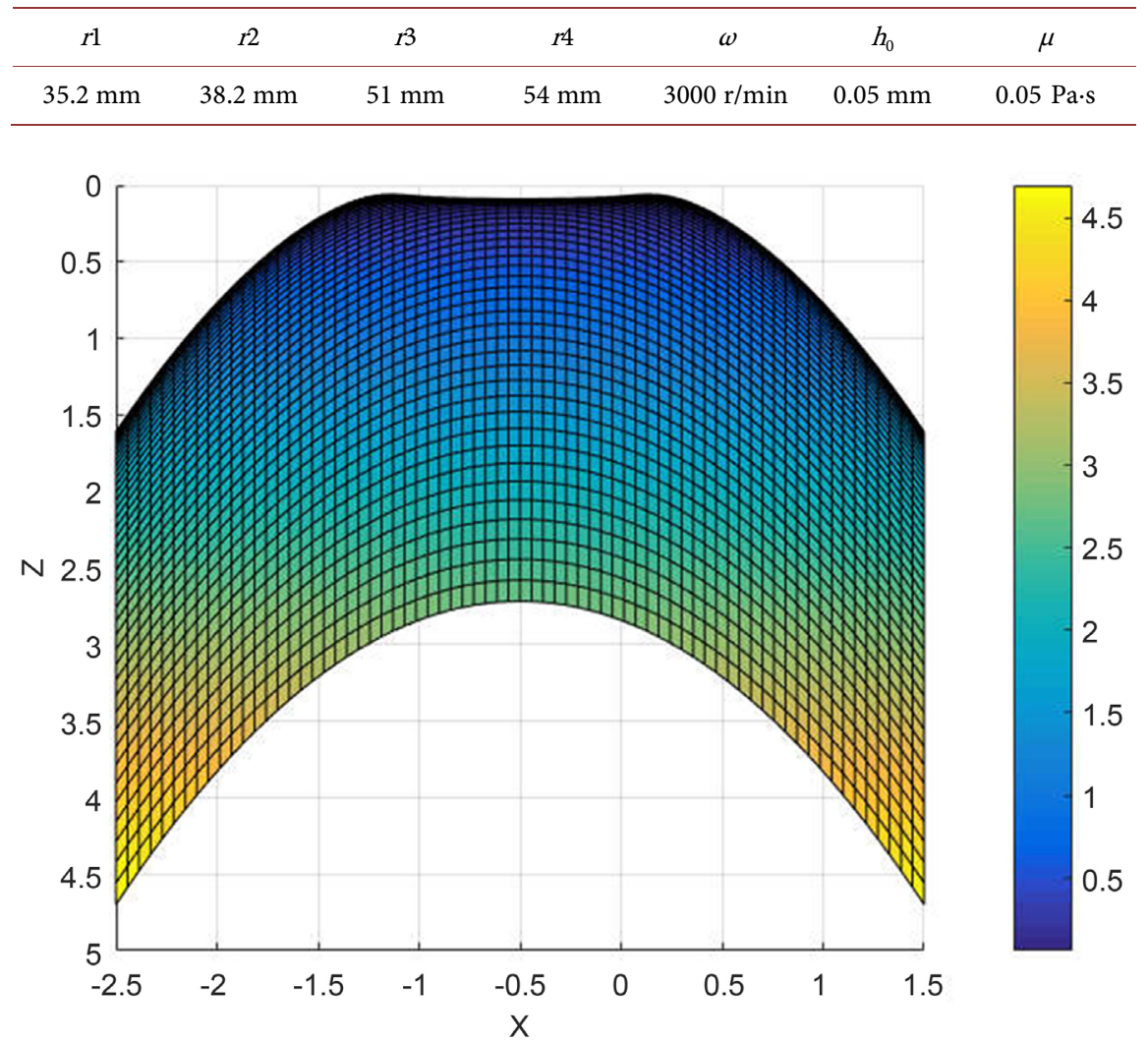

Figure 9. Single texture oil film thickness under fluid solid interaction.

a complete spherical crown. The analysis shows that the maximum dimensionless deformation of oil film thickness at the boundary is 0.247 , and the average oil film thickness increases by $14.4 \%$ compared with that without considering elastic deformation.

Figure 10 shows the pressure distribution diagram of the oil film of the globular microstructure with the optimal texture, which can be seen from the figure.

At the junction between the oil film and the micro-texture surface of the valve plate, the oil film pressure is caused by the elastic deformation of the oil film. It can be seen from the analysis that, at the boundary, the maximum oil film pressure decreased by $8.60 \%$. This is because when considering elastic deformation, the increase of average oil film thickness on the flow distribution surface will weaken the dynamic pressure effect of lubrication by the flow distribution pair. It can also be seen from the figure that, due to the increase of oil film thickness, the flow resistance of the flow distribution surface decreases, thus increasing the high pressure area and bearing capacity of the flow distribution.

\section{Conclusions}

During the process of operation, the valve plate will be deformed due to the extrusion of oil film, and the elastic deformation of the valve plate will exist. 


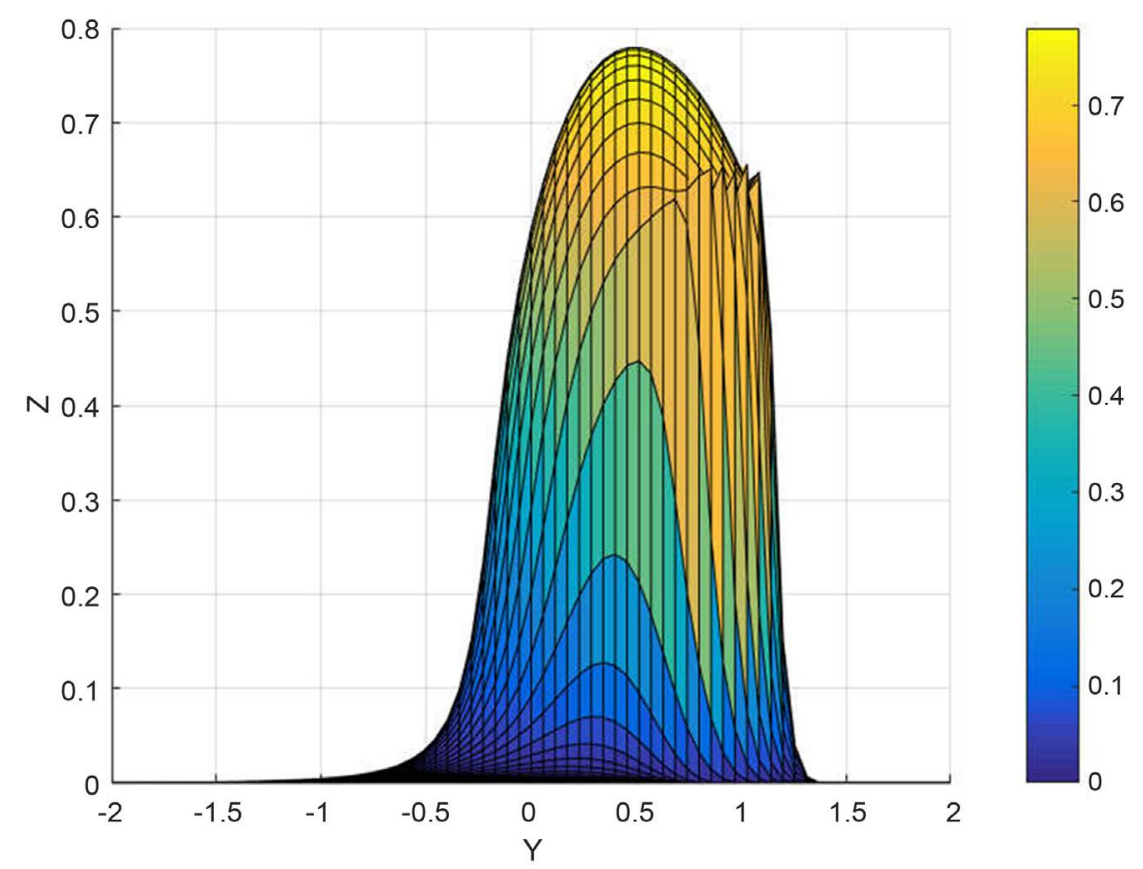

Figure 10. Single texture oil film pressure under fluid solid interaction.

The uneven distribution of oil film thickness and pressure is bound to have a significant impact on the working state and lubrication characteristics of the valve plate.

The simulation study was conducted under the optimal texture of the spherical-shaped microtexture distribution disc. Compared with the distribution disc without considering elastic deformation, the oil film thickness and pressure of the coupled texture distribution disc varied. Compared with the oil film thickness without considering elastic deformation, the average oil film thickness increased by $14.4 \%$, while the maximum oil film pressure decreased by $8.60 \%$.

\section{Conflicts of Interest}

The author declares no conflicts of interest regarding the publication of this paper.

\section{References}

[1] Shin, J.H., Kim, H.E. and Kim, K.W. (2011) A Study on Models for the Analysis of Pressure Pulsation in a Swash-Plate Type Axial Piston Pump. American Journal of Physical Anthropology, 27, 503-518.

[2] Chao, Q., Zhang, J., Xu, B., Chen, Y. and Ge, Y. (2018) Spline Design for the Cylinder Block within a High-Speed Electro-Hydrostatic Actuator Pump of Aircraft. Meccanica, 53, 395-411. https://doi.org/10.1007/s11012-017-0705-2

[3] Bae, J.H., Chung, W.J. and Jang, J.H. (2015) Study of Pressure and Flux Pulsation to Design Optimum Valve-Plate Notch and Pulsation-Variables Analysis of Swash-Plate-Type Piston Pump. Journal of the Korean Society of Manufacturing Technology Engineers, 24, 244-250. https://doi.org/10.7735/ksmte.2015.24.2.244

[4] Zoto, T. and Nagórka, A. (2007) Analysis of the Pressure Distribution of Oil Film in the Variable Height Gap between the Axial Piston Pump and Cylinder Block in the 
Axial Piston Pump. Architectural Institute of Japan, 7, 293-301.

[5] Zhu, Y., Chen, X. and Zou, J. (2015) A Study on the Influence of Surface Topography on the Low-Speed Tribological Performance of Port Plates in Axial Piston Pumps. Wear, 338-339, 406-417. https://doi.org/10.1016/j.wear.2015.07.016

[6] Park, I.K. and Rhim, Y.C. (2009) A Study on the Characteristics of Volumetric Efficiency of an Axial Piston Pump Considering Piston Tilting. Kstle International Journal, 10, 37-42.

[7] Zloto, T. and Kowalski, K. (2012) Pressure Distributions in Oil Film in the Front Gap of a Hydrostatic Thrust Bearing. Institute of Mechanical Technologies Czestochowa University of Technology. Teka Komisji Motoryzacji i Energetyki Rolnictwa, 12, 279-283.

[8] Brown, S.R., Hamilton, G.M. and Moore, S.L. (1975) Hydrodynamic Pressure under a Piston Ring. Nature, 253, 341-342. https://doi.org/10.1038/253341a0

[9] Johnson, K.L. and Roberts, A.D. (1972) Rheology of Oil Films at High Contact Pressures. Nature, 240, 553-554. https://doi.org/10.1038/240553a0

[10] Wang, S. (2014) Robust Design of Piston Assemblies in an Axial Piston Pump. International Journal of Fluid Power, 15, 69-76. https://doi.org/10.1080/14399776.2014.931131

[11] Zloto, T. (2017) Simulation of the Hydrostatic Load of the Valve Plate-Cylinder Block System in an Axial Piston Pump. Procedia Engineering, 177, 247-254. https://doi.org/10.1016/j.proeng.2017.02.196

[12] Pan, H.C., Sheng, J.C. and Lu, Y.X. (1989) Finite Difference Computation of Valve Plate Fluid Film Flows in Axial Piston Machines. International Journal of Mechanical Sciences, 31, 779-791. https://doi.org/10.1016/0020-7403(89)90044-1

[13] Cho, I.S. (2015) A Study on the Optimum Design for the Valve Plate of a Swash Plate-Type Oil Hydraulic Piston Pump. Journal of Mechanical Science \& Technology, 29, 2409-2413. https://doi.org/10.1007/s12206-015-0533-Z

[14] Bergada, J.M., Kumar, S., Davies, D.L. and Watton, J. (2012) A Complete Analysis of Axial Piston Pump Leakage and Output Flow Ripples. Applied Mathematical Modelling, 36, 1731-1751. https://doi.org/10.1016/j.apm.2011.09.016

[15] Wang, B. (2009) Real-Time Measurement on Lubrication Characteristic Parameters of Plane Port Pair in Axial Piston Pumps. Transactions of the Chinese Society for Agricultural Machinery, 40, 209-211.

[16] Ahn, S.Y., Rhim, Y.C. and Hong, Y.S. (2005) Lubrication and Dynamic Characteristics of a Cylinder Block in an Axial Piston Pump. World Tribology Congress III, 2, 223-224. https://doi.org/10.1115/WTC2005-63341

[17] Bergada, J.M., Davies, D.L., Kumar, S. and Watton, J. (2012) The Effect of Oil Pressure and Temperature on Barrel Film Thickness and Barrel Dynamics of an Axial Piston Pump. Meccanica, 47, 639-654. https://doi.org/10.1007/s11012-011-9472-7

[18] Rybicki, E.F., Strenkowski, J.S. and Tamm, M.A. (1978) A Finite Element Model for Compliant Bearing Lubrication Using a Minimization Algorithm. Wear, 47, 279-292. https://doi.org/10.1016/0043-1648(78)90158-8

[19] Mucchi, E., Agazzi, A. and D’Elia, G. (2013) On the Wear and Lubrication Regime in Variable Displacement Vane Pumps. Wear, 306, 36-46. https://doi.org/10.1016/j.wear.2013.06.025

[20] Han, L., Wang, S. and Zhang, C. (2015) A Partial Lubrication Model between Valve Plate and Cylinder Block in Axial Piston Pumps. Proceedings of the Institution of Mechanical Engineers, Part C: Journal of Mechanical Engineering Science, 229, 
3201-3217. https://doi.org/10.1177/0954406214568824

[21] Lin, S. and Hu, J. (2015) Tribo-Dynamic Model of Slipper Bearings. Applied Mathematical Modelling, 39, 548-558. https://doi.org/10.1016/j.apm.2014.06.009

[22] Li, Y., Ji, Z., Yang, L., et al. (2016) Thermal-Fluid-Structure Coupling Analysis for Valve Plate Friction Pair of Axial Piston Pump in Electro-Hydrostatic Actuator (EHA) of Aircraft. Applied Mathematical Modelling, 47, 839-858.

https://doi.org/10.1016/j.apm.2016.08.015 